\title{
Characteristics of Shell Bone as an Identification Tool for Turtle Species (Reptiles: Testudines) in Java, Borneo, and Sumatra
}

\author{
Donan Satria Yudha ${ }^{1 *}$, Fidelis Aritona Triki Sadewa ${ }^{2}$, Rury Eprilurahman ${ }^{1}$ \\ 1) Laboratory of Animal Systematics, Faculty of Biology, Universitas Gadjah Mada, Yogyakarta. Jl. Teknika Selatan Sekip Utara \\ Yogyakarta, 55281 \\ 2) Faculty of Biology, Universitas Gadjah Mada, Yogyakarta. Jl. Teknika Selatan Sekip Utara Yogyakarta, 55281
}

Submitted: 02 July 2019; Accepted: 06 January 2020; Published: 15 April 2020

\begin{abstract}
There are 42 species of turtles; including sea turtle, freshwater turtle, tortoise, and softshell turtle (Reptilia: Testudines) living in Indonesia today. Turtles have economic values for quite a long time and it has led to illegal trade such as smuggling of carapace and plastron bones. Identification is needed to find out more details about the turtle species. Turtles have shells as unique features with different characteristics on each species. Shell's identification usually relies on the shape of carapace and plastron. The purpose of this research is to understand turtle shell morphological characters and determine the diagnostic characters of each species. We conducted visual observation on specimen collections from the Laboratory of Animal Systematics, Faculty of Biology, Universitas Gadjah Mada and Museum of Biology, Faculty of Biology, Universitas Gadjah Mada. The result shows that each turtle species have their own unique shell bone's characters, therefore it can be used to determine each turtle species of Indonesia.
\end{abstract}

Keywords: turtle, bones, carapace, plastron

\section{INTRODUCTION}

There are 42 species of turtles (including sea turtle, freshwater turtles, tortoise, and softshell turtle) living in Indonesia today. However, only five families can be found in the western part of Indonesia (Java, Borneo, and Sumatra) there are: Cheloniidae (sea turtles), Dermochelyidae (leatherback sea turtles), Geoemydidae (freshwater turtles), Testudinidae (tortoises), and Trionychidae (softshell turtles) (Iskandar, 2000; Iverson, 1992; Rhodin et al., 2017). Turtles are a group of taxa that has unique characters and easily distinguished from other reptile groups. They are characterized by external features such as the absence of teeth and the most wellknown is the shell as 'home'. Turtle's shell consists of two parts: the upper part (dorsal) that covers the back is called carapace and the lower part (ventral) is

\footnotetext{
*Corresponding author

Tel.: +6281392665990

Email: donan_satria@ugm.ac.id

(C) 2020, J. Tropical Biodiversity Biotechnology (CC BY-SA 4.0)
}

called plastron. The carapace and plastron have a function to protect the head, limbs, tail, and internal organs of turtle. Turtle's shell originates from a combination of vertebral columns with ribs, sternum and collarbone, and pelvis. The turtle's shell is determined in three general forms based on the nature and level of ossification: hard shells, softshells, and thick skin. As a result, each species of turtles has different shape and characteristics (Das, 2010).

Turtles have been a commodity for humans since ancient times. Most turtles are traded as pets, but some are processed as meat consumption. The high market demand (either export and local consumption) for turtles has triggered illegal hunting and trade (Iskandar, 2000). The turtle meat trade usually leaves shell bones and it can be used for species identification. The identification of turtle species using shells is generally based on the typical characteristics found in turtle shell bones (Sobolik \& Steele, 1996). The paleontologists have used the shell bone to identify fossil turtle. Consequently, there are 
some fossils of turtles in Indonesia that have been identified, among them are Megalochelys sp. and Hardella isoclina Dubois, 1908 (Das, 1997; Joordens et al., 2009; Setiyabudi, 2009).

The purpose of this study is to understand the morphological characteristics of shell bone from several turtle species to determine the diagnostic characters. These characters can be an alternative to identify turtle species. The obtaining results are expected to help people identify shell bones of turtle species, especially for wildlife scientific and management authority (identify illegal trafficking evidence).

\section{MATERIALS AND METHODS}

\section{Materials}

We examined 11 shell bones specimens from eight turtle's species. Specimens' collection of the Laboratory of Animal Systematics, Faculty of Biology, Universitas Gadjah Mada includes: 1) two species of sea turtles Family Cheloniidae (Eretmochelys imbricata and Chelonia mydas); 2) one species of fresh water turtle Family Geoemydidae (Cuora amboinensis); 3) two species of land tortoises Family Testudinidae (Manouria emys and Indotestudo forstenii); and 4) two species of softshell turtle Family Trionychidae (Amyda cartilaginea and Dogania subplana), all with a complete shell bone. Specimens' collection of the Museum of Biology, Faculty of Biology, Universitas Gadjah Mada, includes: 1) one species of sea turtle Family Cheloniidae (Lepidochelys olivacea); 2) one species of land tortoises Family Testudinidae (Manouria emys); and 3) two species of softshell turtle Family Trionychidae (Amyda cartilaginea and Dogania subplana), all with a complete shell bones. For comparison, we used the description of other species: 1) sea turtle Family Cheloniidae (Caretta carreta) and Family Dermochelyidae (Dermochelys coriacea); 2) freshwater turtle Family Geoemydidae (Batagur baska, Orlitia borneensis, Heosemys spinosa, and Leucocephalon yunvonor); 3) softshell turtle Family Trionychidae (Chitra chitra and Pelochelys cantorii) taken from Lydekker (1889), Pritchard et al. (2009), and Eckert et al. (2012). Complete shell bones are generally composed of carapace and plastron (Figure 1.). The carapace consists of nuchal, peripherical, neural, pleural, suprapygal, pygal and supracaudal. The plastron consists of epiplastron, entoplastron, hyoplastron, hypoplastron, xiphiplastron, and bridge. Each fragment is connected by a suture (Brinkman et al., 2017; Pritchard et al., 2009; Sobolik \& Steele, 1996).

\section{Methods}

We conducted visual observation on the turtle's shell bones and literature study to determine the diagnostic character of each species. These characters can be found from each part of carapace and plastron fragments. We also compared the scute sulci and grid on the shell bone's surface. On scaly turtles, scute sulci (Figure 1) are found as a place where the scales attach. In softshell turtles, a pattern will form a grid on the surface of the shell as the skin layer attaches (Iskandar, 2000; Sobolik \& Steele, 1996).

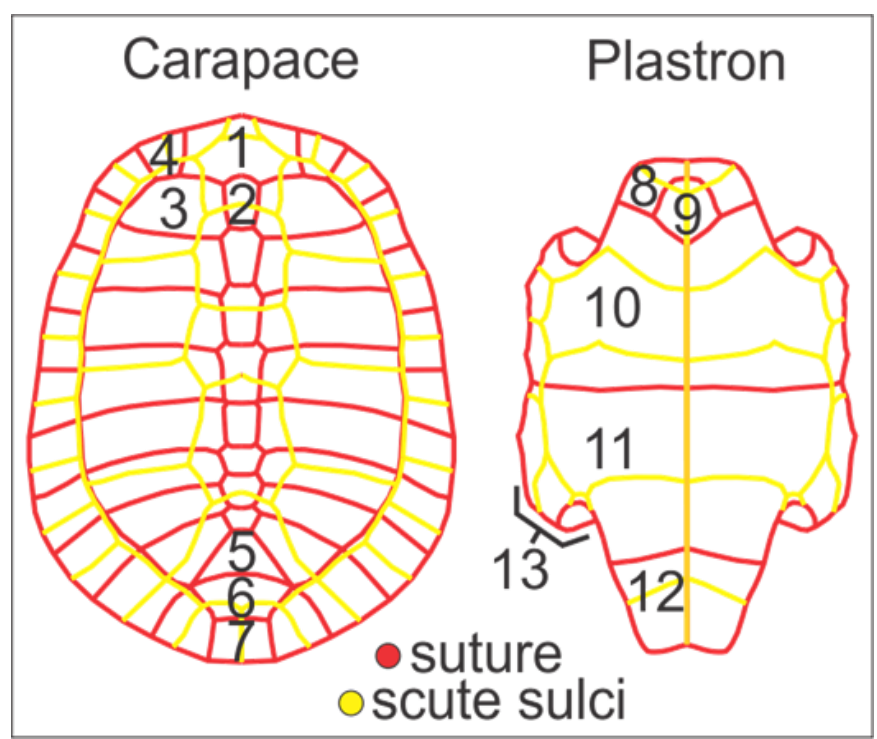

Figure 1. Complete shell bone specimen. Left: dorsal (carapace) view and right: ventral (plastron) view, with description: 1. Nuchal, 2. Neural, 3. Pleural, 4. Peripherical, 5. Suprapygal, 6. Pygal, 7. Supracaudal, 8. Epiplastron, 9. Entoplastron, 10. Hyoplastron, 11. Hypoplastron, 12. Xiphiplastron, 13. Bridge (modified from Lydekker, 1889)

\section{RESULTS AND DISCUSSION}

Sea Turtle Specimen members of the Family Cheloniidae (examined specimens and literature study)

The sea turtle group (family Cheloniidae) consists of four species spread throughout the Indonesian sea. This group is supported by several characters, including the number of plates (scutes) of the carapace and the different parts of plastron. Plastron is divided into three parts. The first part consists of epiplastron and entoplastron which are fused. Other parts are hyoplastron, hypoplastron, and xiphiplastron which are fused, each of them is divided into right and left. The plastron has a fontanel in the middle which split hyo-hypoxiphiplastron right and left, however, the plastron in sea turtle has no bridge (Figure 1).

Lepidochelys olivacea has a solid carapace, where other groups of sea turtles have carapace with fontanel as adults (Figure 2). Plastron of Lepidochelys olivacea has a wide size, without long sutures 
resembling thorns on hyoplastron or hypoplastron. Entoplastron has a wide triangle shape. Caretta caretta has a carapace character with small fontanels. In adults, sometimes there is no fontanel, similar to Lepidochelys olivacea (Figure 2). Plastron of Caretta caretta has a slim morph, with long thorn-like sutures on hyoplastron or hypoplastron.

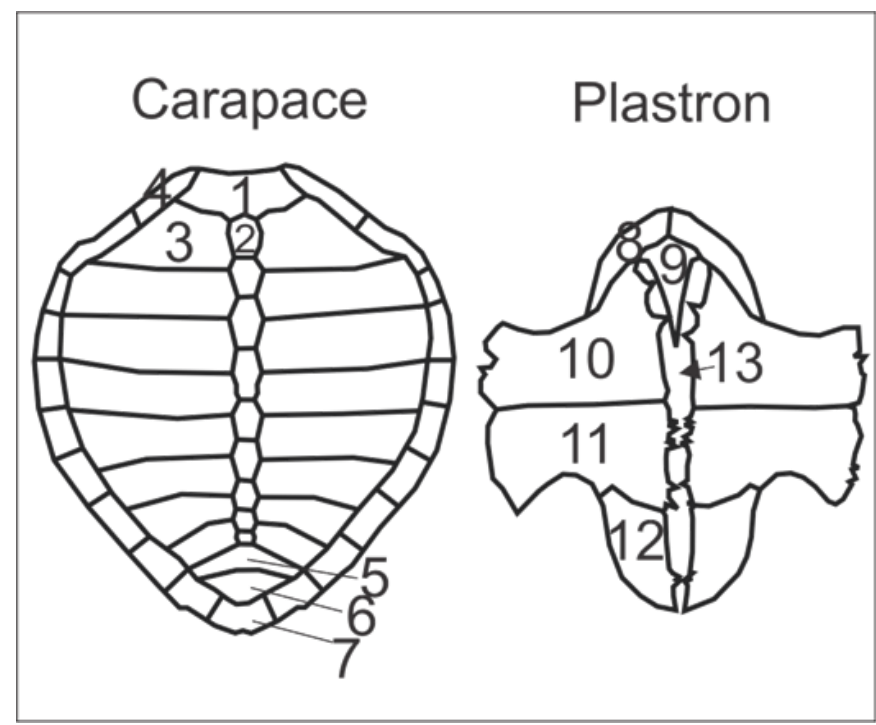

Figure 2. Specimens of Lepidochelys olivacea from Museum of Biology UGM. Left: dorsal (carapace) view and right: ventral (plastron) view, with description: 1. Nuchal, 2. Neural, 3. Pleural, 4. Peripherical, 5. Suprapygal, 6. Pygal, 7. Supracaudal, 8. Epiplastron, 9. Entoplastron, 10. Hyoplastron, 11. Hypoplastron, 12. Xiphiplastron, 13. Fontanel which split between hyo-hypoplastron (Personal documentation, drawn from real skeletal specimen collection of the Museum of Biology, Universitas Gadjah Mada).

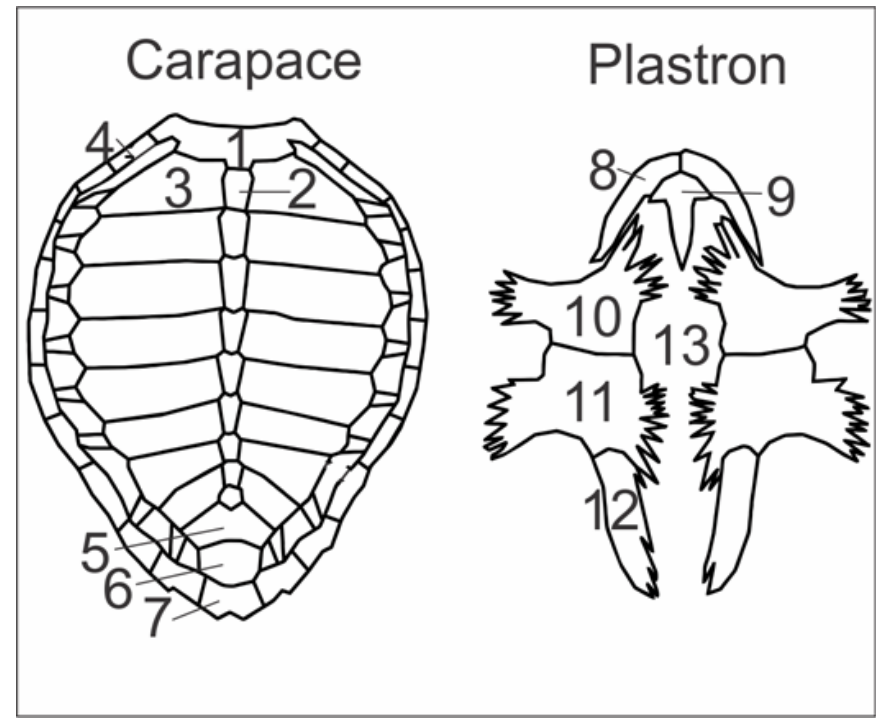

Figure 3. Specimens of Caretta caretta. Left: dorsal (carapace) view and right: ventral (plastron) view, with description: 1. Nuchal, 2. Neural, 3. Pleural, 4. Peripherical, 5. Suprapygal, 6. Pygal, 7. Supracaudal, 8. Epiplastron, 9. Entoplastron, 10. Hyoplastron, 11. Hypoplastron, 12. Xiphiplastron, 13. Fontanel which split between hyo-hypoplastron (modified from Valente, 2007).
Sutures of Caretta caretta tend to cluster on each side. Entoplastron has a tack-like shape, with a fairly wide center. Eretmochelys imbricata has many fontanels in the carapace. Fontanels are used for forming the flexibility of carapace bones so they can resist the underwater pressure when diving. This character also found in Chelonia mydas. The pleural part has a dagger-like shape, with the rib cage covered by a carapace shield plate (Figure 4).

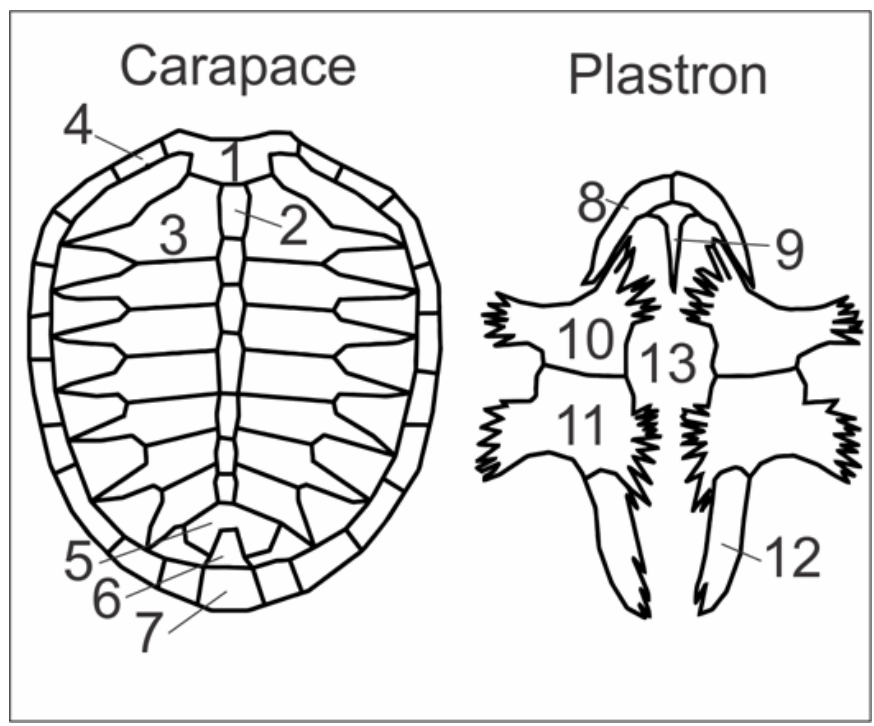

Figure 4. Specimens of Eretmochelys imbricata from the Laboratory of Animal Systematics, Faculty of Biology, UGM. Left: dorsal (carapace) view and right: ventral (plastron) view, with description: 1. Nuchal, 2. Neural, 3. Pleural, 4. Peripherical, 5. Suprapygal, 6. Pygal, 7. Supracaudal, 8. Epiplastron, 9. Entoplastron, 10. Hyoplastron, 11. Hypoplastron, 12. Xiphiplastron, 13. Fontanel which split between hyo-hypoplastron (modified from Wyneken, 2001).

The plastron of Eretmochelys imbricata has a morphological form that resembles Caretta caretta (Figure 3). However, the distinguishing character is in the entoplastron section. The entoplastron of Eretmochelys imbricata has a narrower shape in the middle. The last species of sea turtle group is Chelonia mydas. The carapace of Chelonia mydas is not completely ossified, so there are many fontanels. In the pleural part, the rib cage is partially exposed, because it is not covered with a carapace shield plate (Figure 5).

Plastron of Chelonia mydas has the least morphology with ossification compared to other species of sea turtles. Hyoplastron has not many spines but extends individually on each spine. The spine of a suture in the hypoplastron looks more clustered and slightly dense. Chelonia mydas entoplastron has the slimmest form than the other sea turtles, resembling a plus sign (Figure 5). 


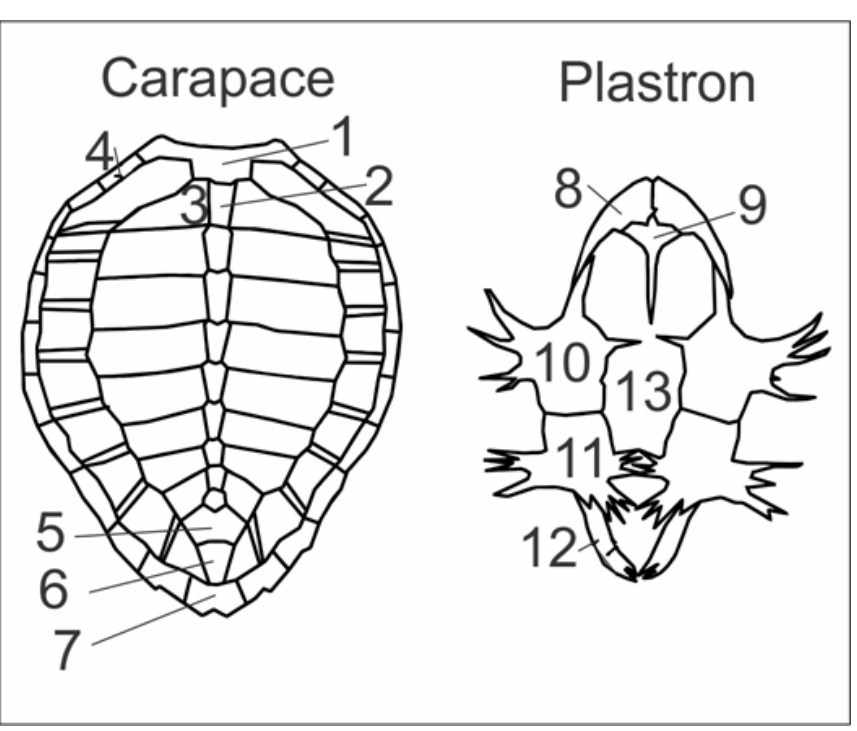

Figure 5. Specimens of Chelonia mydas from Museum of Biology UGM. Left: dorsal (carapace) view and right: ventral (plastron) view, with description: 1. Nuchal, 2. Neural, 3. Pleural, 4. Peripherical, 5. Suprapygal, 6. Pygal, 7. Supracaudal, 8. Epiplastron, 9. Entoplastron, 10. Hyoplastron, 11. Hypoplastron, 12. Xiphiplastron, 13. Fontanel which split between hyo-hypoplastron (modified from Grace, 2012).

Sea Turtle Specimens members of the Family Dermochelyidae (literature study)

The leatherback sea turtle group (Dermochelyidae) only has one species that still alive today, it is Dermochelys coriacea. This group shows the level of neotony skeletons that are more advanced than other species members of the order Testudines. Only the nuchal bone has no sutural contact with other bones and relatively intact. Pleural bone, which in other members of the Testudines generally forms together with the ribs in a composite bone structure, is not found in this species. The ribs are thin, so they have morphology as found in hard-shelled turtle embryos. Peripheral, suprapygal, pygal, and supracaudal bone were not found in this group (Figure 6).

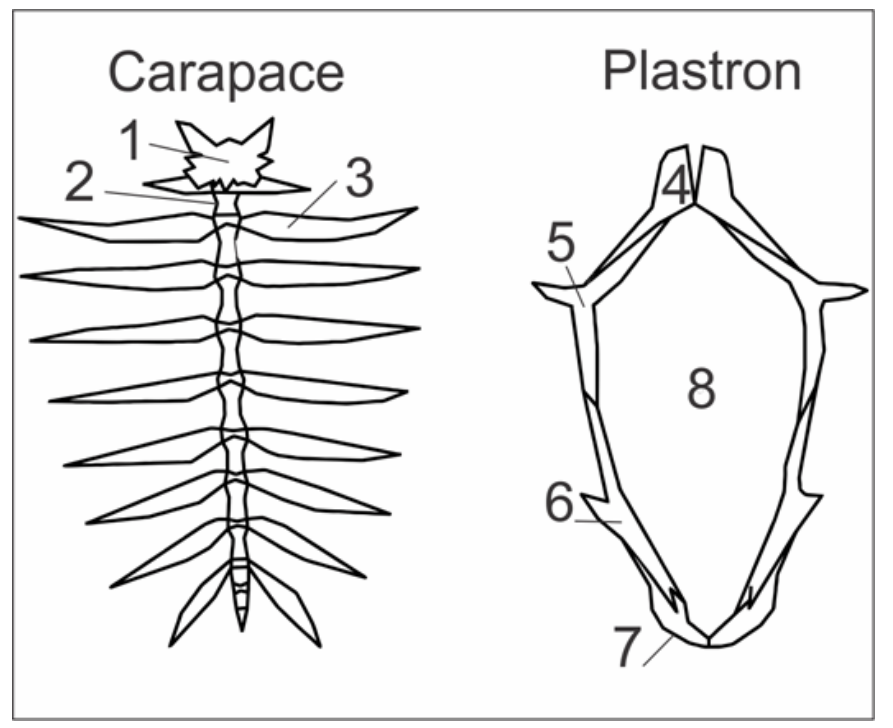

Figure 6. Specimens of Dermochelys coriacea. Left: dorsal (carapace) view and right: ventral (plastron) view, with description: 1. Nuchal, 2. Neural, 3. Pleural, 4. Epiplastron, 5. Hyoplastron, 6. Hypoplastron, 7. Xiphiplastron, 8. Very large fontanel (modified from Eckert et al., 2012).

Dermochelys coriacea has plastron without entoplastron. But the remaining elements (epiplastron, hyoplastron, hypoplastron, and xiphiplastron) are reduced to a narrow structure, fused to form a ring around a large and open middle fontanel (Figure 6). Leatherback turtle shells thus obtain very high flexibility from their reinforced core structures. It appears that the shell, especially the plastron, has a very large reduced ossification, can resist substantially to accommodate the extreme pressure at a deep sea.

Freshwater turtle specimens' members of the Family Geoemydidae (literature study)

The group of freshwater turtles (family Geoemydidae) is the group that has the most members in western Indonesia. This turtle has the most complete diagnostic character among the other members of the Testudines, for example, taken in the Batagur baska (Figure 7).

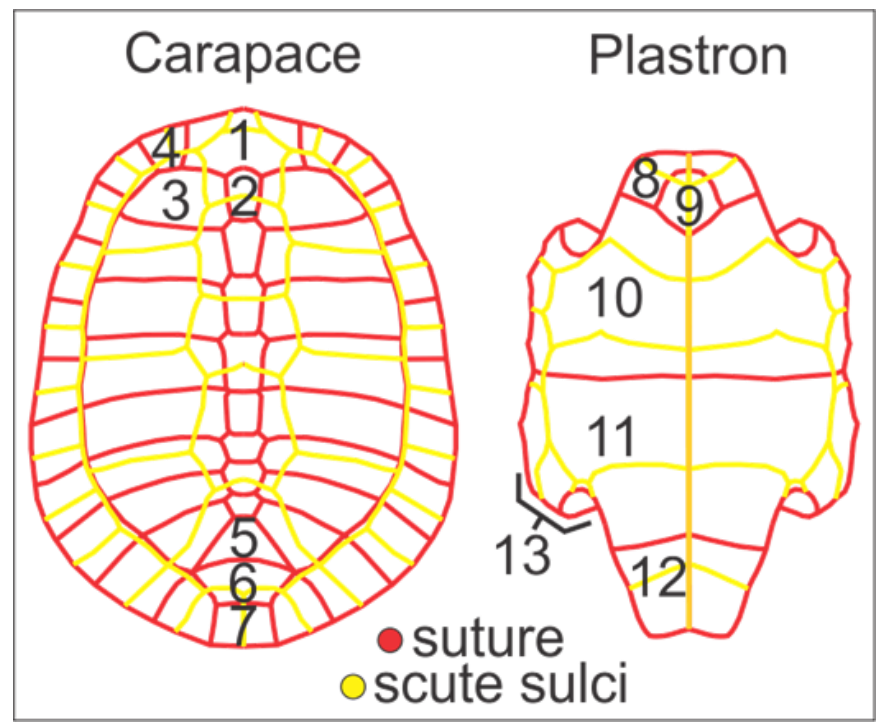

Figure 7. Specimens of Batagur baska. Left: dorsal (carapace) view and right: ventral (plastron) view, with description: 1. Nuchal, 2. Neural, 3. Pleural, 4. Peripherical, 5. Suprapygal, 6. Pygal, 7. Supracaudal, 8. Epiplastron, 9. Entoplastron, 10. Hyoplastron, 11. Hypoplastron, 12. Xiphiplastron (modified from Lydekker, 1889).

In the members of this group, the whole shell is covered with keratin scales, so that in the shell bone you will see a line of sticky scales called scute sulci. In this group, there is no fontanel when adults. In addition, pleural is arranged uniformly because 


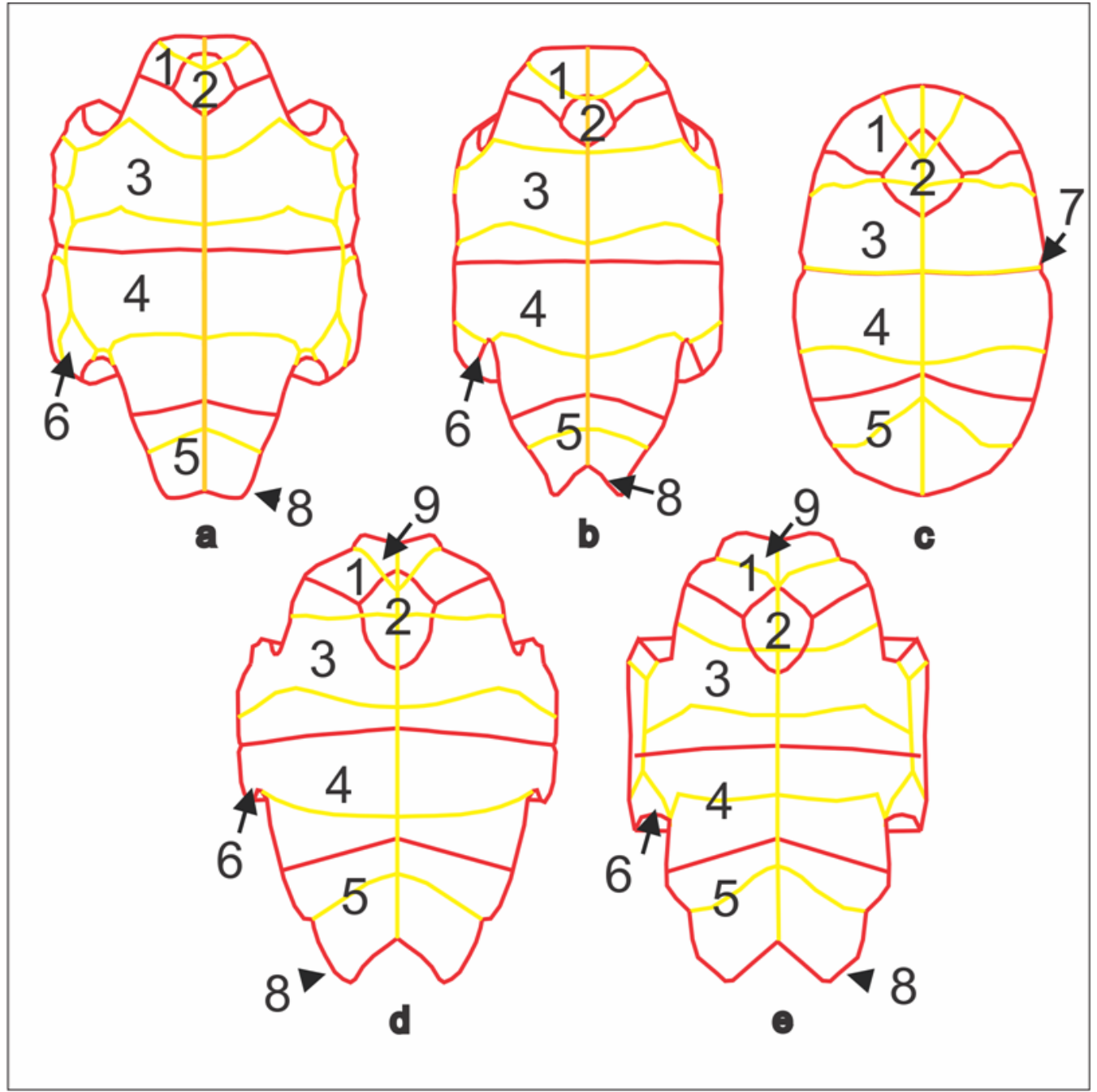

Figure 8. Plastron of various species members of the Geoemydidae. a. Batagur baska, b. Orlitia borneensis, c. Cuora amboiensis, d. Heosemys spinosa, e. Leucocephalon yumonoi, with descriptions: 1. Epiplastron, 2. Entoplastron, 3. Hyoplastron, 4. Hypoplastron, 5. Xiphiplastron, 6. Bridge, 7. Hinge, 8. Anal notch, 9. Gular notch (modified from Lydekker, 1889; Pritchard et al., 2009; \& personal documentation).

the morphology is relatively the same. The carapace section is very difficult to use as a distinguishing character between species. Then the character diagnostic focuses on the plastron morphological characters (Figure 8).

At the Batagur baska, the diagnostic characters found in epiplastron and xiphiplastron forms that are elongated and narrow, likely to be slender. The shell suture is only owned by young individuals. On adult specimens, the shell bone fragments fused and the suture developed into ankylosis form. In the hyoplastron fragment, there are scute sulci which do not cross entoplastron. The bridge part is elongated and clear, so the overall shape of the plastron resembles a plus sign. The anal notch is not too concave (Figure 8a). In Orlitia bormeensis, the diagnostic character that can be seen clearly is the hyoplastron part which has scute sulci, and do not cross entoplastron. In addition, the anal notch looks very concave (Figure $8 b$ ).

Cuora amboinensis has a diagnostic character in the hyoplastron section that only has one scute sulci and cut entoplastron. Dual scute sulci which generally found in hyoplastron of turtles, only found a single in Cuora amboinensis, as a result, one of the scute sulci which has fused with suture in part called hinge (Figure 8c). Heosemys spinosa has a diagnostic character in the form of gular notch and anal notch which form to be concave. Two scute sulci found in the hyoplastron, one of which is cutting the entoplastron (Figure 8d). In Leucocephalon yuwonoi, the diagnostic character is seen from the form of $\mathrm{Y}$ scute sulci (three branches) in hyoplastron and hypoplastron (Figure 8e)

Tortoise specimens' members of Family Testudinidae (examined specimens and literature study)

The group of tortoises (family Testudinidae) has a diagnostic character that has many similarities to members of the freshwater turtle (family Geoemydidae). The two groups can be distinguished based on the form of pleural arrangement. In members of the Testudinidae have a pleural shape 

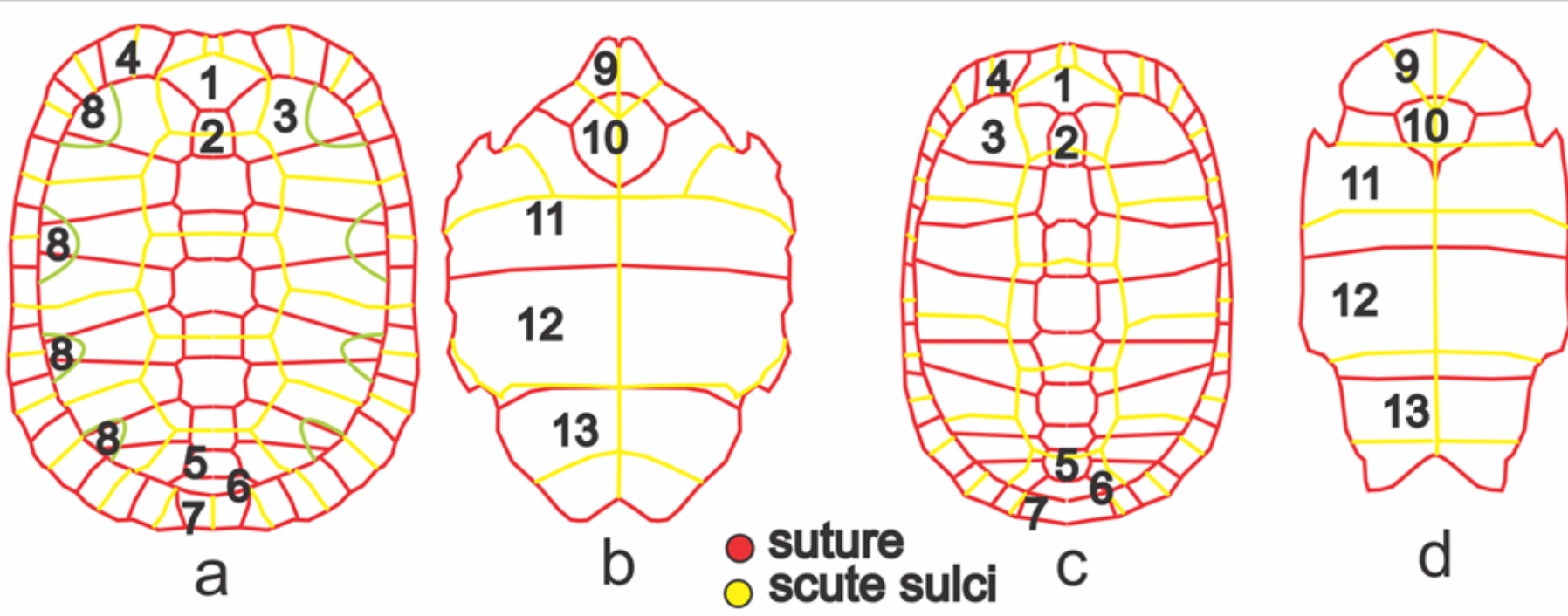

Figure 9. Shell bone specimens' members of Testudinidae. a. Manouria emys carapace, b. Indotestudo forstenii carapace, c. Manouria emys plastron, d. Indotestudo forstenii plastron, with descriptions: 1. Nuchal, 2. Neural, 3. Pleural, 4. Peripherical, 5. Suprapygal, 6. Pygal, 7. Supracaudal, 8. Parts that geodesics, 9. Epiplastron, 10. Entoplastron, 11. Hyoplastron, 12. Hypoplastron, 13. Xiphiplastron (modified from Brinkman, 2017; \& Personal documentation).

that is not the same between the base of the pleural which is connected with the neural, and the pleural end that is connected with peripherical. So that the pleural shape that belongs to this family tends to be trapezoidal. The pleural arrangement is found in the carapace forms a zigzag pattern (Figure 9). There are two species of tortoises which was found in Indonesia, there are Manouria emys and Indotestudo forstenii. Although Indotestudo forstenii is not found in western Indonesia, the same genus Indotestudo elongata, is found in the Southeast Asia region near to western Indonesia, so we include it in this study.

In the carapace of Manouria emys has a diagnostic character of geodesics, where thickening of the ossification occurs in the area around scute sulci. Whereas other parts (including the part of the suture) that are not close to scute sulci will be thinning out (Figure 9a). Epiplastron forms a spear. Hyoplastron has a scute sulci pattern forming $\mathrm{Y}$ (Figure 9c). Not many characteristic in the carapace Indotestudo forstenii, except the overall shape is more elongated compared to Manouria emys (Figure 9b). The diagnostic character of this species is the presence of a thick epiplastron forming a bumper (Figure 9d).

Softshell Turtle Specimens members of Family Trionychidae (examined specimens and literature study)

Members of the softshell turtle (family Trionychidae) have a distinctive shell character compared to other members of the order Testudines. There is a much reduction in shell configuration, loss of scales and replaced by soft and rough skin. Shells have no peripherical bones so the ribs are exposed. Supracaudal was not found, but the bone was replaced by a pair of pygal bones. The plastron consists of seven parts, epiplastron, entoplastron, hyoplastron, xiphiplastron hypoplastron. Overall, the plastron is not connected, except in the hyoplastron and hypoplastron which are joined by sutures. Entoplastron has a shape like a boomerang. Epiplastron elongated and narrow (Figure 10).

\section{Carapace}

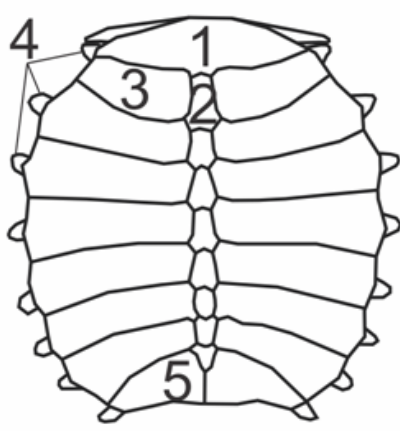

\section{Plastron}

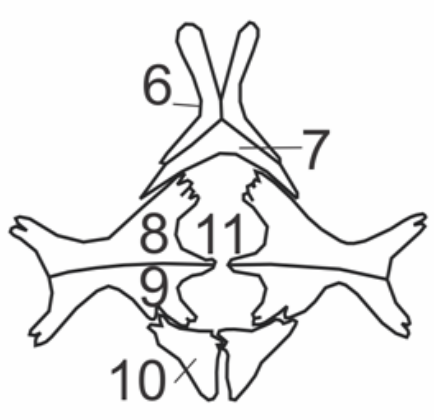

Figure 10. Specimens of Amyda cartilaginea, left: dorsal (carapace) view and right: ventral (plastron) view, with description: 1. Nuchal, 2. Neural, 3. Pleural, 4. Ribs, 5. Pygal, 6. Epiplastron, 7. Entoplastron, 8. Hyoplastron, 9. Hypoplastron, 10. Xiphiplastron, 11. Fontanel (redrawn from Iskandar, 2000)

In softshell turtles, the basic character for species identification is the latticed patterns on shell bone's surface. This pattern can be found in all parts of the carapace and plastron of this group. In western Indonesia, there are four species of softshell turtles: Amyda cartilaginea, Dogania subplana, Chitra chitra, and 
Table 1. Shell bone diagnostic character.

\begin{tabular}{|c|c|c|c|}
\hline No & Species & Characters & Remarks \\
\hline \multicolumn{4}{|c|}{ Family Cheloniidae } \\
\hline \multirow[t]{3}{*}{1} & Lepidochelys olivacea & Carapace & Solid with no fontanel \\
\hline & & Plastron & Without long suture spines \\
\hline & & Entoplastron & Wide triangle shape \\
\hline \multirow[t]{3}{*}{2} & Caretta caretta & Carapace & Partly fontanelled \\
\hline & & Plastron & Grouped long suture \\
\hline & & Entoplastron & Tack-like shape (wide at center) \\
\hline \multirow[t]{4}{*}{3} & Eretmochelys imbricata & Carapace & Fontanelle $50 \%$ pleural \\
\hline & & Pleural & Dagger-like shape,Covered ribs \\
\hline & & Plastron & Grouped long suture \\
\hline & & Entoplastron & Thin tack-like shape \\
\hline \multirow[t]{4}{*}{4} & Chelonia mydas & Carapace & Fontanelle $50 \%$ pleural \\
\hline & & Pleural & Uncovered ribs \\
\hline & & Plastron & Long suture and not grouped \\
\hline & & Entoplastron & Cross-like shape \\
\hline \multicolumn{4}{|c|}{ Family Dermochelyidae } \\
\hline \multirow[t]{3}{*}{5} & Dermochelys coriacea & Carapace & $\begin{array}{l}\text { Only consists of nuchal, neural and } \\
\text { pleural }\end{array}$ \\
\hline & & Pleural & Dagger-like shape \\
\hline & & Plastron & Ringed fontanel without entoplastron \\
\hline \multicolumn{4}{|c|}{ Family Geomydidae } \\
\hline \multirow[t]{2}{*}{6} & Batagur baska & Shell & Ankylosis \\
\hline & & Plastron & $\begin{array}{l}\text { Epiplastron and xiphiplastron are } \\
\text { elongated and slender }\end{array}$ \\
\hline 7 & Orlitia borneensis & Hyoplastron & Scute sulci without cuts entoplastron \\
\hline \multirow[t]{2}{*}{8} & Cuora amboinensis & Hyoplastron & Single scute sulci with hinge \\
\hline & & Plastron & Without bridge \\
\hline 9 & Heosemys spinosa & Hyoplastron & Scute sulci cuts entoplastron \\
\hline 10 & Leucocephalon yuwonoi & Hyo-hypoplastron & Triangular scute sulci, Y shape \\
\hline \multicolumn{4}{|c|}{ Family Testudinidae } \\
\hline 11 & Indotestudo forstenii & Plastron & Epiplastron bumper shape \\
\hline 12 & Manouria emys & Carapace & Geodesics \\
\hline \multicolumn{4}{|c|}{ Family Trionychidae } \\
\hline 13 & Amyda cartilaginea & Shell pattern & Mosaic with hill \\
\hline$\overline{14}$ & Dogania subplana & Shell pattern & $\begin{array}{l}\text { Near the neural is mosaic, near the } \\
\text { marginal is vermiform with } \\
\text { protuberance }\end{array}$ \\
\hline 15 & Chitra chitra & Shell pattern & $\begin{array}{l}\text { Near the neural is an overlapping } \\
\text { circle, near the marginal is vermiform }\end{array}$ \\
\hline 16 & Pelochelys cantorii & Shell pattern & $\begin{array}{l}\text { Near the neural is a circle with bold a } \\
\text { border, near the marginal, is } \\
\text { vermiform }\end{array}$ \\
\hline
\end{tabular}

Pelochelys cantorii. In Amyda cartilaginea, it has the same pattern between neural and marginal parts. The pattern looks random and irregular to form a mosaic. In addition, there is a hill (in the illustration shown by a thicker line) which is scattered and longitudinally parallel to the neural (Figure 11a). In Dogania subplana, the approach to neural patterns looks similar to the mosaic-shaped pattern (cf. Amyda cartilaginea). But the obvious difference is based on a deep and firm crater on Dogania subplana. The approaching marginal shell pattern looks slightly sloping and vermiform, with the presence of nodules (Figure 11b). Chitra chitra has a circular pattern that overlaps at the neural part but towards the marginal direction, the pattern changes into a vermiform form (Figure 11c). Pelochelys cantorii has a pattern that is not different from Chitra chitra. In the neural part, the pattern is dominated by a circle that has clear 


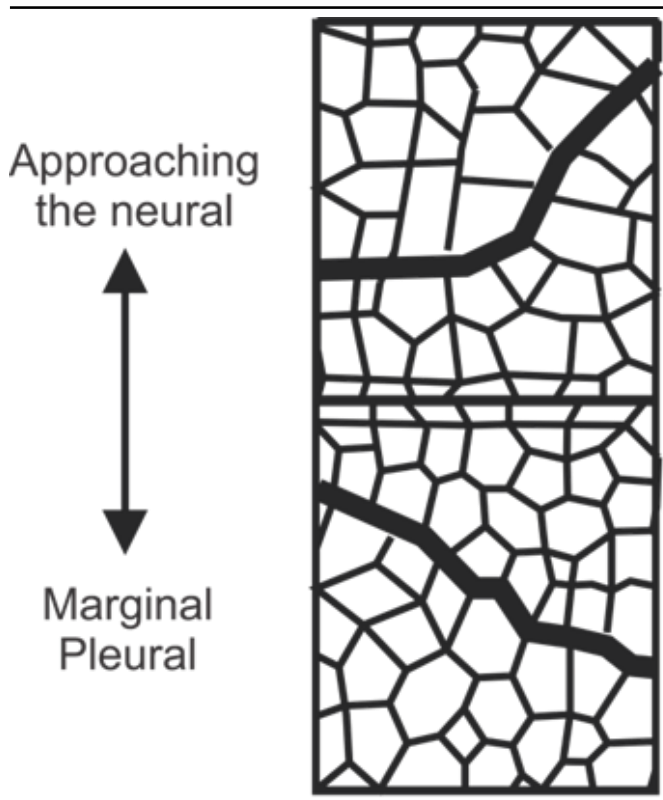

a

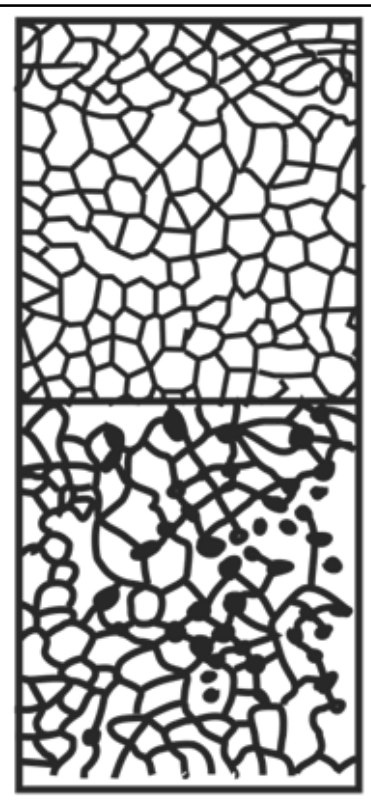

b

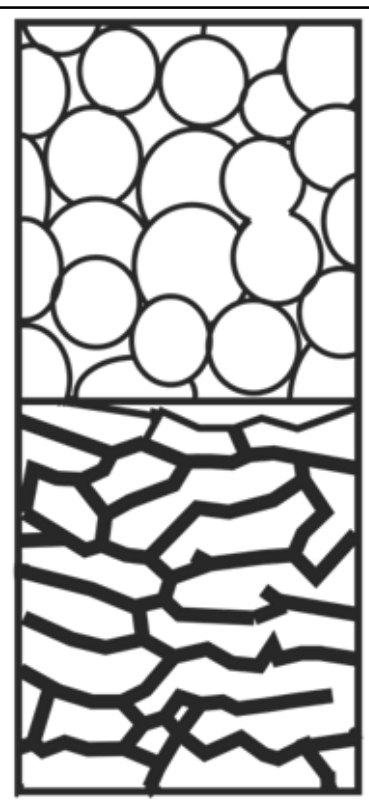

C

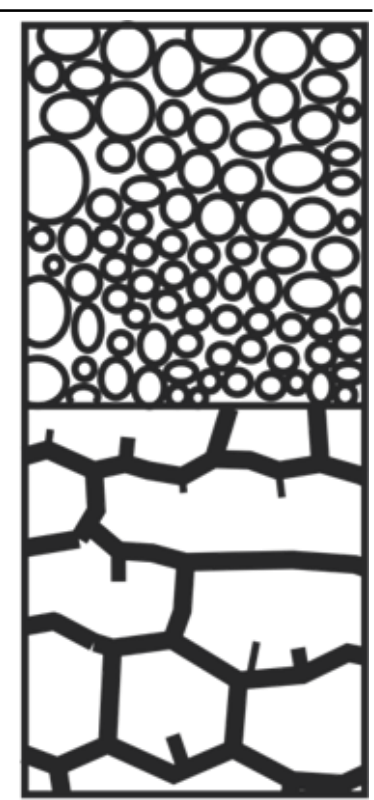

d

Figure 11. Shell pattern of the Trionychidae members. Above: approaching neural, bottom: marginal pleural, a. Amyda cartilaginea, b. Dogania subplana, c. Chitra chitra, d. Pelochelys cantorii (modified from Pritchard et al., 2009)

boundaries and does not overlap. Towards marginal, the pattern is replaced by a sloping vermiform form (Figure 11d).

\section{Diagnostic Character of each Turtle Shell}

Based on the results of the analysis, we determined the diagnostic characteristics of each species (Table 1).

\section{CONCLUSION}

This research is important in contributing to the turtle's species identification based on their shell bones composition. The sea turtles species can be identified by the carapace's fontanelle form and location, carapace's bone solidity, and the different forms and groups of plastron's suture spines. Softshell turtles species are identified from their shell pattern with or without a mosaic hill, vermiform shape, and their protuberance. Freshwater and semiaquatic turtles species are identified from the shape of scute sulci. These characters are useful to determine the species of turtle which are sold by illegal trading or fragments fossil found in Java. Further studies with more specimens from other turtle species are needed to make a complete identification key.

\section{REFERENCES}

Brinkman, D., Rabi, M. \& Zhao, L., 2017, Lower Cretaceous fossils from China shed light on the ancestral body plan of crown softshell turtles (Trionychidae, Cryptodira), Scientific Report 7, 6719 (2017), 1-11.
Das, I., 2010, A Field Guide to the Reptiles of South-East Asia, pp. 168, 173, 174, 175, New Holland Publishers, London..

Das, I., 1997. A reassessment of Hardella isoclina dubois, 1908 (Testudines: Bataguridae) from the trinil beds of the Javan Pleistocene (Short Notes), Herpetological Journal, 7(2), 71-73.

Eckert, K.L., Wallace, B.P., Frazier, J.G., Eckert, S.A. \& Pritchard, P.C.H., 2012, Synopsis of the Biological Data on the Leatherback Sea Turtle (Dermochelys coriacea), Biological Technical Publication, BTP-R4015-2012.

Grace, K., 2012. Florida Museum of Natural History, viewed 3 November 2018. from https://www.floridamuseum.ufl.edu/science/ sea-turtle-herpetology-collection-photos/

Iskandar, D.T., 2000, Kura-kura dan Buaya Indonesia dan Papua Nugini: dengan catatan mengenal jenisjenis di Asia Tenggara, pp. 51-53; 57-62; 69-70; 77-84; 98, Institut Teknologi Bandung, Bandung.

Iverson, J.B., 1992, A Revised Checklist with Distribution Maps of the Turtles of the World, pp. 80-91; 98, 101; 242-280; 292, Privately Printed, Richmond, Indiana.

Joordens, J.C. A., Wesselingh, F.P., de Vos, J.,Vonhof, H.B. \& Kroon, D., 2009, Relevance of aquatic environments for hominins: a case study from Trinil (Java, Indonesia), Journal of Human Evolution 57, 656-671. 
Lydekker, R., 1889, Catalogue of the Fossil Reptilia and Amphibia in the British Museum (Natural History), Cromwell Road, S.W., Part III (Containing the Order CHELONIA), p.125, Order of the Trustees, London.

Pritchard, P.C.H., Rabett, R.J. \& Piper, P., 2009, Distinguishing Species of Geoemydid and Trionychid Turtles from Shell Fragments: Evidence from the Pleistocene at Niah Caves, Sarawak, International Journal of Osteoarchaeology, 19(4), 531-550.

Rhodin, A.G.J., Iverson, J.B., Bour, R., Fritz, U., Georges, A., Shaffer, H.B. \& van Djik, P.P., 2017, Turtles of the World Annotated Checklist and Atlas of Taxonomy, Synonymy, Distribution, and Conservation Status 8th pp. 9-14; 27-32; 83-86; 140; 145; 162-173, Chelonian Research Foundation, Massachusetts.
Setiyabudi, E., 2009, An early Pleistocene giant tortoise (Reptilia; Testudines; Testudinidae) from the Bumiayu area, Central Java, Indonesia, Journal of Fossil Research, 42(1), 1-11.

Sobolik, K.D. \& Steele, D.G., 1996, A Turtle Atlas to Facilitate Archaeological Identification, pp. 1-3; 4; 27, Mammoth Site of Hot Springs, Inc., South Dakota.

Valente, A.L.S., 2007, Diagnostic Imaging of the Loggerhead Sea Turtle (Caretta caretta), Thesis, Universitas Autonoma de Barcelona, Bellaterra.

Wyneken, J., Godfrey, M.H. \& Bels, V., 2008, Biology of Turtles, CRC Press, Boca Raton. 